Jpn. J. Oral Biol., 25 : 139-144, 1984.

\title{
ストロンチウムおよびバリウムハイドロ キシアパタイトの溶解度積
}

\author{
倉田茂昭藤 原 努 根岸秀幸 \\ 山崎 升藤 瀬 精 一 \\ 神奈川歯科大学化学教室 (主任 : 山崎 升) \\ [受付：昭和58年12月19日]
}

\section{Solubility product of strontium and barium hydroxyapatite}

\author{
Shigeaki Kurata, Tsutomu Fujiwara, Hideyuki \\ Negishi, Noboru Yamazaki and Seiichi Fujise* \\ Department of Chemistry, Kanagawa Dental College
}

82, Inaoka-cho, Yokosuka 238, *3599-881, Fujisawa, Fujisawa 251

(Chief : Prof. Noboru Yamazaki)

[Accepted for publication: December 1983]

Key words : strontium / barium / apatite / activity solubility product

\begin{abstract}
Strontium and barium hydroxyapatite ( $\mathrm{SrHA}$ and $\mathrm{BaHA}$ ) which are stoichiometrically composed and crystalline, were prepared by solid state reaction. Equilibrium of $\mathrm{SrHA}$ in dilute $\mathrm{HC}_{4} 0_{4}$ aqueous solution in the $\mathrm{pH}$ range 6-8 and $\mathrm{BaHA}$ in dilute $\mathrm{KOH}$ aqueous solution in the $\mathrm{pH}$ range 10-11 were accomplished at $37^{\circ} \mathrm{C}$ respectively.

Activity solubility products of the hydroxyapatite were calculated from concentration of metal cation, phosphorus and $\mathrm{pH}$ in the equilibrium solution, as the $\mathrm{Ksp}$ values of $\mathrm{SrHA}$ and $\mathrm{BaHA}$ were $10^{-106 \pm 1}$ and $10^{-88.0 \pm 0,4}$ respectively. The $\mathrm{Ksp}$ values of both apatite, $\mathrm{SrHA}$ and $\mathrm{BaHA}$, were slightly greater than that of calcium hydroxyapexite (Ksp: $10^{-115}$ ). The activity solubility products of the apatites increased with the radius of cation used.

According to considerations in the enthalpy of hydration of the ion and lattice energy of each apatite crystall, it was assumed that the differences of the solubility products of the apatites depended on the difference in lattice energy.
\end{abstract}

\section{緒言}

歯牙ら蝕の主因は 口腔内の細菌から産生された 有機酸による歯牙の脱灰とされていることから， 歯牙およびその 主成分であるカルシウムハイドロ キシアパタイト（以後， CaHA と略す）の溶解性 については, これまでにも多数研究が行なわれて きた。しかしながら，歯牙は $\mathrm{CaHA}$ の組成であ る $\mathrm{Ca}^{2+}, \mathrm{PO}_{4}{ }^{3-}, \mathrm{OH}^{-}$以外に微量の無機イオン

神奈川県横須賀市稲岡町82（广 238）

* 神奈川県藤沢市藤沢 3599-98 ( $\bar{T} 251$ )
や有機質を含むため，その溶解性はかなり複雑な 挙動を示す。特にこれらの無機イオンは $\mathrm{CaHA}$ 結晶の格子中のイオンと置換し，そのために歯牙 の酸に対する溶解性や再石灰化に大きな影響を及 ぼすものと考えられる。これら無機イオンの中で も, $\mathrm{Sr}^{2+}$ と $\mathrm{Ba}^{2+}$ はたとえ微量であっても $\mathrm{Ca}^{2+}$ と同じ II A 族であるため, 特にその影響が重要 である。 $\mathrm{Sr}^{2+} や \mathrm{Ba}^{2+}$ については，これまで歯牙 のう蝕を幾分おさえるという報告もあるが'1,2)， 逆に $\mathrm{Sr}^{2+}$ は歯牙の耐酸性にあまり寄与しない3， また $\mathrm{Ba}^{2+}$ は再石灰化を防ぐという研究などがあ 
り ${ }^{4}$ ，必ずしもまだ充分説明されたとは言えな い。このように矛循した結果が得られるのは，こ れらカチオンが歯牙の主体をなす $\mathrm{CaHA}$ の溶解 性に複雑な影響を与えるからであると考えられ る。

そこで本研究では，これらイオンが $\mathrm{CaHA} の$ 溶解性におよぼす影響を調べる基礎として, Sr と $\mathrm{Ba}$ のハイドロキシアパタイト（以後, $\mathrm{SrHA}$, $\mathrm{BaHA}$ と略す）の溶解度積を求め, $\mathrm{CaHA}$ の值 と比較検討した。

\section{実験}

\section{1. $\mathrm{SrHA}, \mathrm{BaHA}$ の調製}

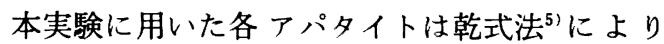
調製した。すなわち，Sr と Ba のオルトリン酸 塩に 5 倍モルの各金属炭酸塩を粉砕混合し，水蒸 気雾囲気, $1100^{\circ} \mathrm{C}$ 電気炉中で約 12 時間加熱した。 冷却後，過剩の金属イオンを除くため反応物を 10 $\%-\mathrm{NH}_{4} \mathrm{Cl}$ 溶液で洗浄, 次に $\mathrm{NH}_{4}{ }^{+}$がなくなる まで蒸留水で洗浄後, $120^{\circ} \mathrm{C}$ で乾燥し, $\mathrm{SrHA}$ と BaHA を得た。

得られた各アパタイトは化学分析, 粉末 X線回 折により確認した。化学分析の 結果を Table 1 に示す。なお $\mathrm{Sr}$ および $\mathrm{Ba}$ は DTPA キレート 試薬を用いた亜鉛標準液による逆滴定，Pはバナ ドモリブデン酸発色による比色法で定量した。

Table 1 Chemical analysis of apatites

\begin{tabular}{c|c|c|c}
\hline & $\mathrm{M}(\%)$ & $\mathrm{P}(\%)$ & $\mathrm{M} / \mathrm{P}$ \\
\hline \multirow{2}{*}{ SrHA } & $\begin{array}{c}59.0 \\
(59.2)\end{array}$ & $\begin{array}{c}12.5 \\
(12.6)\end{array}$ & $\begin{array}{c}1.67 \\
(1.67)\end{array}$ \\
\hline \multirow{2}{*}{ BaHA } & $\begin{array}{c}68.7 \\
(69.5)\end{array}$ & $\begin{array}{c}9.34 \\
(9.40)\end{array}$ & $\begin{array}{c}1.66 \\
(1.67)\end{array}$ \\
\hline
\end{tabular}

( ) Theoretical as $\mathrm{M}_{10}\left(\mathrm{PO}_{4}\right)_{6}(\mathrm{OH})_{2}$

2. アパタイト溶液の調製と溶解量の測定

アパタイト溶液の調製: SrHA と BaHA の溶 解度積の測定のため, 安定な $\mathrm{pH}$ 域 ${ }^{6}$ を与えるこ とが知られている $\mathrm{HClO}_{4}$ 溶液と $\mathrm{KOH}$ 溶液をそ れぞれ用いた。各アパタイトの添加量は, SrHA の場合, $\mathrm{HClO}_{4}$ の $0.05,0.10,0.25,0.50,1.0$ $\mathrm{mM}$ の各溶液にアパタイトをそれぞれ 0.10 , $0.15,0.25,0.50 \mathrm{~g}$ 加え, 合計20個とし, $\mathrm{BaHA}$
の場合, $\mathrm{KOH}$ の $0.5,1.0,1.5,2.0,2.5,3.0$ $\mathrm{mM}$ の各溶液にアパタイトをそれぞれ0.1，0.15， $0.20 \mathrm{~g}$ を加え合計 30 個の試料を調製した。

溶解量の測定 : 種々の濃度のアパタイト溶液 $20 \mathrm{~m} l$ つつをポリプロピン製試験管にとり，窒素 ガス気流下で封管し， $37^{\circ} \mathrm{C}$ 恒温槽中で 2 週間 振盪した。この振盪時間については予備実験を 行い，各溶液とも充分平衡に達したことを確認 した。二週間後, 懸濁液をミリポアフィルター $(0.22 \mu \mathrm{m}$ pore size $)$ に通し, ろ液の $\mathrm{pH}$, 金属イ オン, りんを分析した。なお $\mathrm{Sr}$ と $\mathrm{Ba}$ は $\mathrm{C}_{2} \mathrm{H}_{2}$ $\mathrm{N}_{2} \mathrm{O}$ を用いた炎光分析, $\mathrm{P}$ は上述の 比色分析に より定量した。次にそれら分析值を用い各アパタ イトの溶解度積を計算した。

\section{3. 溶解度積の計算}

溶解度積を算出するために 用いた式ならびに諸 定数を Table 2 に示す。ただし，Table 2 中お よび以後の文章においてイオンの電荷は省略す る。ここで Ksp は求めるアパタイトの熱力学的 溶解度積, Mは $\mathrm{Sr}$ あるいは $\mathrm{Ba}, \mathrm{f}$ は各イオンの 活量係数, $\mathrm{Kw}$ は水のイオン積, $[\mathrm{M}]_{\mathrm{obs}},[\mathrm{P}]_{\mathrm{obs}}$ そして $[\mathrm{H}]_{\mathrm{obs}}$ は分析より得た金属イオン，りんそ して水素イオン濃度を表わす。

Ksp を算出するためにまず各イオンの活量係数 $f_{M}, f_{P O 4}, f_{H}, f_{\text {oH }}$ を Debye-Hückel 式より求めた ${ }^{\circ}$

$$
-\operatorname{logfi}=\frac{0.52 \mathrm{zi}^{2} \sqrt{\mathrm{Ii}}}{1+0.33 \mathrm{a} \sqrt{\mathrm{Ii}}}
$$

ここで fi は各イオンの活量係数, $\mathrm{Zi}$ は電荷, a はイオンパラメーターを表わす11)。なお各アパタ イト溶液中のイオン強度 $\mathrm{I}_{\mathrm{sr}}$ あるいは $\mathrm{I}_{\mathrm{Ba}}$ は, 溶 液中に存在する各イオンの濃度を考慮すると次式 で与えられる。

$$
\mathrm{I}_{\mathrm{Sr}}=\frac{1}{2}
$$

$$
\left(\left[\mathrm{ClO}_{4}\right]+\left[\mathrm{H}_{2} \mathrm{PO}_{4}\right]+4\left[\mathrm{HPO}_{4}\right]+4[\mathrm{Sr}]\right)
$$

$$
\text { or } \mathrm{I}_{\mathrm{Ba}}=\frac{1}{2}
$$

$$
\left([\mathrm{K}]+[\mathrm{OH}]+4\left[\mathrm{HPO}_{4}\right]+9\left[\mathrm{PO}_{4}\right]+4[\mathrm{Ba}]\right)
$$

ここで $\left[\mathrm{ClO}_{4}\right],[\mathrm{K}]$ は各試料溶液により定めら

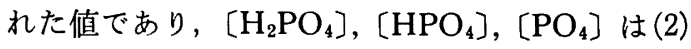
式を用いて溶液中の水素イオン 濃度の関数として 導びかれ, [OH] は $\mathrm{Kw} /[\mathrm{H}]_{\text {obs }}$ より得られ, 
Table 2 Calculating procedure and equilibrium constants

\begin{tabular}{|c|c|c|}
\hline Equilibrium and calculation expression & constant & ref. \\
\hline \multicolumn{3}{|l|}{$\begin{array}{l}\text { Activity solubility product for the apatites; } \\
\mathrm{Ksp}=\left([\mathrm{M}] \cdot \mathrm{f}_{\mathrm{M}}\right)^{10} \cdot\left(\left[\mathrm{PO}_{4}\right] \cdot \mathrm{f}_{\mathrm{PO}_{4}}\right)^{6} \cdot\left([\mathrm{OH}] \cdot \mathrm{f}_{\mathrm{OH}}\right)^{2} \cdots(1)\end{array}$} \\
\hline $\begin{array}{l}\text { Dissociation of phosphoric acid; } \\
\begin{aligned} \mathrm{K}_{1} & =\left[\mathrm{H}_{3} \mathrm{PO}_{4}\right] /\left([\mathrm{H}] \cdot\left[\mathrm{H}_{2} \mathrm{PO}_{4}\right]\right) \\
\mathrm{K}_{2} & =\left[\mathrm{H}_{2} \mathrm{PO}_{4}\right] /\left([\mathrm{H}] \cdot\left[\mathrm{HPO}_{4}\right]\right) \cdots \cdots(2) \\
\mathrm{K}_{3} & =\left[\mathrm{HPO}_{4}\right] /\left([\mathrm{H}] \cdot\left[\mathrm{PO}_{4}\right]\right)\end{aligned}\end{array}$ & $\begin{array}{l}\mathrm{K}_{1}=171 \\
\mathrm{~K}_{2}=1.46 \times 10^{7} \\
\mathrm{~K}_{8}=1.51 \times 10^{12}\end{array}$ & 7) \\
\hline \multirow{2}{*}{$\begin{array}{l}\text { Formation of } \mathrm{M} \text {-phosphate complexes; } \\
\qquad \begin{aligned} \mathrm{K}_{4} & =\left[\mathrm{MH}_{2} \mathrm{PO}_{4}\right] /\left([\mathrm{M}] \cdot\left[\mathrm{H}_{2} \mathrm{PO}_{4}\right]\right) \\
\mathrm{K}_{5} & =\left[\mathrm{MHPO}_{4}\right] /\left([\mathrm{M}] \cdot\left[\mathrm{HPO}_{4}\right]\right) \quad \cdots(3) \\
\mathrm{K}_{6} & =\left[\mathrm{MPO}_{4}\right] /\left([\mathrm{M}] \cdot\left[\mathrm{PO}_{4}\right]\right)\end{aligned}\end{array}$} & $\begin{aligned} \mathrm{Sr} ; \mathrm{K}_{4} & =2.00 \\
\mathrm{~K}_{5} & =15.8 \\
\mathrm{~K}_{6} & =1.58 \times 10^{4}\end{aligned}$ & 8) \\
\hline & $\begin{aligned} \mathrm{Ba} ; \mathrm{K}_{4} & =0 \\
\mathrm{~K}_{5} & =238 \\
\mathrm{~K}_{6} & =3.05 \times 10^{4}\end{aligned}$ & $*_{1}$ \\
\hline $\begin{array}{l}\text { Formation of } M \text {-hydroxide complexes; } \\
\qquad \mathrm{K}_{7}=[\mathrm{MOH}] /([\mathrm{M}] \cdot[\mathrm{OH}]) \cdots \cdots \cdots(4)\end{array}$ & $\begin{array}{l}\mathrm{Sr} ; \mathrm{K}_{7}=7.24 \\
\mathrm{Ba} ; \mathrm{K}_{7}=4.89\end{array}$ & 9) \\
\hline
\end{tabular}

Calculating procedure;

$[\mathrm{M}]$ obs $=[\mathrm{M}]+\left[\mathrm{MH}_{2} \mathrm{PO}_{4}\right]+\left[\mathrm{MHPO}_{4}\right]+\left[\mathrm{MPO}_{4}\right]+[\mathrm{MOH}]$

$[\mathrm{P}]$ obs $=\left[\mathrm{PO}_{4}\right]+\left[\mathrm{H}_{3} \mathrm{PO}_{4}\right]+\left[\mathrm{H}_{2} \mathrm{PO}_{4}\right]+\left[\mathrm{HPO}_{4}\right]+\left[\mathrm{MH}_{2} \mathrm{PO}_{4}\right]+\left[\mathrm{MHPO}_{4}\right]+\left[\mathrm{MPO}_{4}\right]$

$[\mathrm{M}]=[\mathrm{M}] \mathrm{obs} /\left(\gamma+\mathrm{m} \cdot\left[\mathrm{PO}_{4}\right]\right)$

$\left[\mathrm{PO}_{\mathbf{4}}\right]=[\mathrm{P}]_{\mathrm{obs}} /(\mathrm{n}+\mathrm{m} \cdot[\mathrm{M}])$

$[\mathrm{OH}]=\mathrm{K}_{\mathrm{w}} /\left([\mathrm{H}]_{\mathrm{obs}} \cdot \mathrm{f}_{\mathrm{OH}}\right) \cdot$

where are

$\gamma=1+\mathrm{K}_{7} \cdot[\mathrm{OH}], \mathrm{m}=\mathrm{K}_{2} \cdot \mathrm{K}_{3} \cdot \mathrm{K}_{4} \cdot[\mathrm{H}]^{2}+\mathrm{K}_{3} \cdot \mathrm{K}_{5} \cdot[\mathrm{H}]+\mathrm{K}_{6}$

$\mathrm{n}=1+\mathrm{K}_{1} \cdot \mathrm{K}_{2} \cdot \mathrm{K}_{3} \cdot[\mathrm{H}]^{3}+\mathrm{K}_{2} \cdot \mathrm{K}_{3} \cdot[\mathrm{H}]^{2}+\mathrm{K}_{3} \cdot[\mathrm{H}],[\mathrm{H}]=[\mathrm{H}] \mathrm{obs} / \mathrm{f}_{\mathrm{H}}$

*1; obtained by our laboratory

[Sr］と［Ba] は得られた分析值をそのまま代入 した。

次に遊離の[M]および $\left[\mathrm{PO}_{4}\right]$ を求める。本 実験の溶液中では，（1）式の平衡の他にりん酸の 解離 [(2)式]，金属イオンと各種りん酸イオンの 錯体の生成 [(3)式], 金属イオンと $\mathrm{OH}$ の錯体の 生成 [(4)式] の三つの平衡が考えられる。それ ゆえ, 分析より得た $[\mathrm{M}]_{\mathrm{obs}}$ および $[\mathrm{P}]_{\mathrm{obs}}$ は (1) 〜 (4) 式の四つの平衡に関与する種々の化学種の 総和となる[Table 2 の (5), (6) 式]。そこで (2) 〜 (4) 式を用い（5）と（6）式の右辺第二項以下 の化学種を遊離の〔M]と $\left[\mathrm{PO}_{4}\right]$ で表わすと (7) と (8) 式が得られる。この (7) と (8) の連立方程 式を解けば $[\mathrm{M}],\left[\mathrm{PO}_{4}\right]$ が求められる。

最後に, [OH] の值は上述した $\mathrm{f}_{\mathrm{OH}}$ の值を(9) 式に代入することにより得られる。
以上の各イオンの活量係数 $\mathrm{f}_{\mathrm{M}}, \mathrm{f}_{\mathrm{PO} 4}, \mathrm{f}_{\mathrm{OH}}$ と遊離

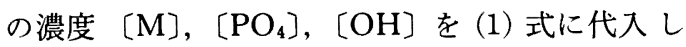
て，アパタイトの熱力学的溶解度積 $\left(\mathrm{K}_{\mathrm{sp}}\right)$ を算出 した。

\section{結果および考察}

1. $\mathrm{SrHA}, \mathrm{BaHA}$ の溶解度積

Table 2 と 3 に0.15g の SrHA および BaHA を溶解した場合の溶液の濃度, 溶解二週間後の溶 液の $\mathrm{pH}$, 溶液中の金属イオンおよびりんの濃度, それら分析值より算出した溶解度積の逆対数值 （pKsp）を示す。また SrHA および BaHA のす べての試料より得た $\mathrm{pKsp} の$ 平均は, それぞれ $106 \pm 1 ， 86.0 \pm 0.4$ であった。ただし，士の後の 数値は $95 \%$ 信頼区間を示す。

$\mathrm{BaHA}$ の溶解度積の值はこれまでに報告されて 
Table 3 SrHA equilibrium solution in $\mathrm{HClO}_{4}$ aqueous solution at $37^{\circ} \mathrm{C}^{* 1}$

\begin{tabular}{c|c|c|c|c}
\hline $\begin{array}{c}\mathrm{HC10} \\
\mathrm{mmol} / l\end{array}$ & {$[\mathrm{H}]$ obs } & $\begin{array}{c}{[\mathrm{Sr}] \mathrm{obs}} \\
\mathrm{mmol} / l\end{array}$ & $\begin{array}{c}{[\mathrm{P}] \mathrm{obs}} \\
\mathrm{mmol} / l\end{array}$ & $\mathrm{pKsp}$ \\
\hline 0.05 & 7.47 & 0.170 & 0.0894 & 105 \\
0.10 & 7.39 & 0.193 & 0.108 & 105 \\
0.25 & 7.07 & 0.307 & 0.165 & 106 \\
0.50 & 6.88 & 0.479 & 0.300 & 105 \\
1.00 & 6.52 & 0.840 & 0.479 & 107 \\
\hline
\end{tabular}

* 1 apatite $0.15 \mathrm{~g}$

Table 4 BaHA equilibrium solution in $\mathrm{KOH}$ aqueous solution at $37^{\circ} \mathrm{C}^{* 1}$

\begin{tabular}{c|c|c|c|c}
\hline $\begin{array}{c}\mathrm{KOH} \\
\mathrm{mmol} / l\end{array}$ & {$[\mathrm{H}]$ obs } & $\begin{array}{c}{[\mathrm{Ba} \text { obs }} \\
\times 10^{-2} \\
\mathrm{mmol} / l\end{array}$ & $\begin{array}{c}{[\mathrm{P}] \text { obs }} \\
\times 10^{-2} \\
\mathrm{mmol} / l\end{array}$ & pKsp \\
\hline 0.5 & 10.32 & 13.0 & 5.66 & 84.2 \\
1.0 & 10.60 & 10.2 & 5.23 & 84.0 \\
1.5 & 10.77 & 8.36 & 5.49 & 83.9 \\
2.0 & 10.90 & 7.15 & 5.76 & 83.8 \\
2.5 & 11.07 & 6.35 & 6.02 & 83.5 \\
3.0 & 11.08 & 5.40 & 6.21 & 84.2 \\
\hline
\end{tabular}

$*_{1}$ apatite $0.15 \mathrm{~g}$

ないが，SrHA の值については次のような報告が ある。

Maurice ${ }^{131}$ は $\mathrm{Sr}(\mathrm{OH})_{2}$ に $\mathrm{H}_{3} \mathrm{PO}_{4}$ を加えた $\mathrm{Sr}$ $(\mathrm{OH})_{2}-\mathrm{H}_{3} \mathrm{PO}_{4}-\mathrm{H}_{2} \mathrm{O}$ 系でSrHA を沈殿させた実験 から溶解度積を求め, pKsp で約 $112\left(\right.$ at $\left.25^{\circ} \mathrm{C}\right)$ を得た。しかし， SrHA の安定域はアルカリ側に あり ${ }^{6)}$ ，上述の系では SrHA 以外のりん酸塩が生 成する可能性があり，正確な值が得られない。 Ronald ら ${ }^{14}$ は合成 $\mathrm{SrHA}$ の希 $\mathrm{H}_{3} \mathrm{PO}_{4}$ 溶液にお ける pKsp として $103 \pm 2\left(\right.$ at $\left.25^{\circ} \mathrm{C}\right)$ を得たが, アパタイトのほかはりん酸の解離平衡しか考慮し ていない。そのため得られた溶解度積も本実験値 に比べ大きくなったものと考えられる。

以上のように本実験で得た溶解度積の值は, $\mathrm{SrHA}$ および $\mathrm{BaHA}$ について各試料間にバラッ キもなく，種々の平衡を考慮しており，信頼性の 高いものと考えられる。

2. CaHA, SrHA および BaHA 間の溶解度 積の差について

次に同じ II A 族に属する $\mathrm{Ca}, \mathrm{Sr}, \mathrm{Ba}$ のアパ
タイトの溶解度積を比較してみよう。本教室で同 様な実験により得た CaHA の溶解度積 $10^{-115}$ と 比べると，その大きさは次の順となり，

$$
\mathrm{CaHA}<\mathrm{SrHA}<\mathrm{BaHA}
$$

Ksp $10^{-115} \quad 10^{-106} \quad 10^{-86.0}$

SrHA および BaHA は CaHA に比べ溶解しや すいことが分る。また Fig. 1 に示すようにアパ タイトの $\mathrm{pKsp}$ と金属のイオン半径は直線関係に あることがわかる。

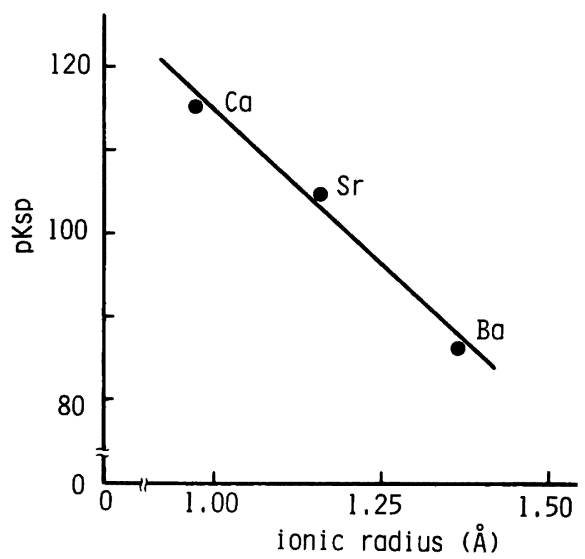

Fig. 1 The pKsp values of CaHA, SrHA and $\mathrm{BaHA}$ on radius of metal cations

一般に同型の結晶性固体の間における溶解量の 差は, 結晶の安定性を示す格子ェネルギー (LE) とその 固体が溶解した溶液の安定性を示す水和エ ネルギー（HE）の差を比べることにより推察でき る。本実験のように陰イオン $\left(\mathrm{PO}_{4}{ }^{3-}\right.$ と $\left.\mathrm{OH}^{-}\right)$が 同じ場合は，金属イオンの $\mathrm{HE}$ とアパタイトの LE を比べればよい。しかしながら，各アパタイ トの LE の值が得られてないため, 害際に数值を 用い溶解量の差を調べることはできない。そこで 本研究で得られた 溶解度積の值から逆に三つのア パタイト間の溶解度の差が LE と HE のどちら に大きく影響されるかを検討した。

Fig. 2 にイオン半径 ${ }^{51}$ に対する各金属イオンの $\mathrm{HE}$ の值 ${ }^{16)}$ と考察の便宜上三つのアパタイトの LE のとりうる傾向を $\mathrm{a} \sim \mathrm{c}$ で示した。この $\mathrm{LE}$ については上述のように 絶対值は不明だがイオン

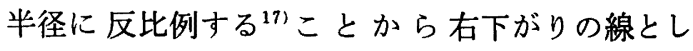
た。

a は LE がイオン半径と共に HE と同傾向で 


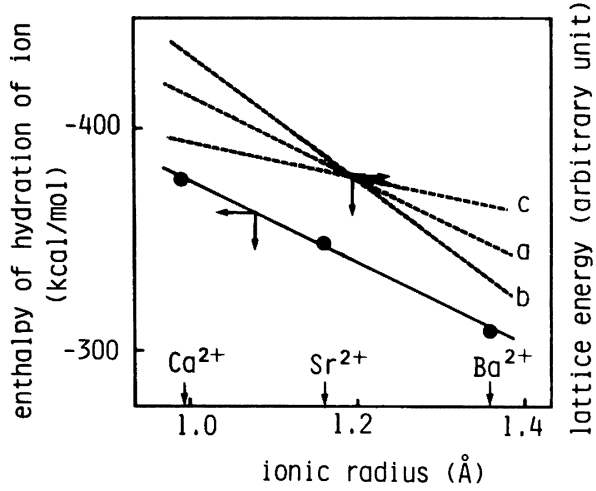

Fig. 2 The enthalpy of hydration of ion and creative lattice energy on radius of metal cations.

减少する場合，各アパタイトとも HE と LE の 差は等しい，すなわち結晶と溶解溶液の安定性に 差がないから溶解度にも差を生じないだろう。 b は HE に比べ LE の変化が大きい (LE の影 響が強い）場合， $\mathrm{Ba}$ よりも $\mathrm{Ca}$ で $\mathrm{HE}$ と $\mathrm{LE}$ の差が大きく, $\mathrm{CaHA}$ が結晶として安定となり $\mathrm{BaHA}$ よりも溶解度は小さくなる。 $\mathrm{c}$ は $\mathrm{b}$ の逆 で HE の変化が大きい（HE の影響が強い）場 合, $\mathrm{Ca}$ よりも $\mathrm{Ba}$ で $\mathrm{HE}$ と LE の差が大きく, $\mathrm{BaHA}$ が結晶として安定となり BaHA の溶解度 は $\mathrm{CaHA}$ より小さくなると考えられる。

以上のごとく b 場合が Fig. 1 のイオン半径 の増加と共に溶解度積が大きくなるという結果を 満たすから，II A 属アパタイト間の溶解度積の差 は水和エネルギーより格子エネルギーによる影響 が強いと推察される。この説明では各アパタイト の Ksp が非常に小さいことから $\mathrm{HE}<\mathrm{LE}$ という 条件で説明したが HE>LE でも溶解性の傾向に ついては同じ結論が得られる。

また溶解度は溶液中の各種 イオン間の錯体の安
定性（この場合金属イオンと各種りん酸イオン） にも影響される。しかし，この錯体の安定度定数 の大きさは, $\mathrm{Sr} \fallingdotseq \mathrm{Ba}<\mathrm{Ca}$ となり $($ Table 2 と 7) ) 安定度定数の大きい $\mathrm{Ca}$ をつ $\mathrm{CaHA}$ の溶解度 が逆に小さくなることから，この錯体の影響は無 視できるものと考えられる。

次に $\mathrm{Sr}$ および $\mathrm{Ba}$ の歯質におよぼす影響につ いて述べる。これまでの微量の $\mathrm{Sr}$ は $\mathrm{CaHA}$ の 結晶の乱札を大くすること神拉よび SrHA や $\mathrm{BaHA}$ が $\mathrm{CaHA}$ より溶解しやすいという本研究 の結果から，歯牙の中に存在する $\mathrm{Sr}$ や Ba は, 歯牙の溶解性にむしろ 悪い影響を与えるものと考 えられる。

\section{結論}

化学量論的組成をもち，しかも結晶性の良い SrHA および BaHA を乾式法により合成し，こ れを用いて溶解度積を求め, 合せて $\mathrm{CaHA}$ の值 と比較検討した。その結果次のことが明らかとな った。

（1） $37^{\circ} \mathrm{C}$ において $\mathrm{SrHA}$ は $\mathrm{HClO}_{4}$ 溶液 中, $\mathrm{pH} 6 \sim 8$ で, $\mathrm{BaHA}$ は $\mathrm{KOH}$ 溶液中, $\mathrm{pH}$ 10 11 で溶解平衡が得られ, 溶解度積はそれぞれ

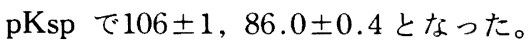

（2）溶解度積の大きさは次の順となり, SrHA と BaHA は共に CaHA より溶解しやすい。

$$
\mathrm{CaHA}<\mathrm{SrHA}<\mathrm{BaHA}
$$

Ksp $\quad 10^{-115} \quad 10^{-106} \quad 10^{-86.0}$

（3）各種金属イオンの水和およびアパタイト 結晶の格子のエネルギーについての考察から，こ れらアパタイト間の溶解度積の差は水和 エネルギ ーよりも各アパタイト結晶の格子エネルギーの差 によるものと推察された。

抄録 : 化学量論的組成をもち, しかも結晶性の良いストロンチウムおよびバリウムハイドロキシアパタイ

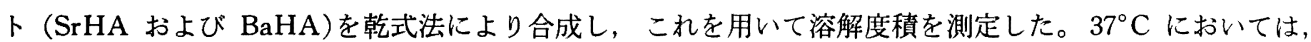
$\mathrm{SrHA}$ について希 $\mathrm{HClO}_{4}$ 溶液中, $\mathrm{pH} 6 \sim 8$ の籁囲で, $\mathrm{BaHA}$ について希 $\mathrm{KOH}$ 溶液中, $\mathrm{pH}$ 10 11の 範囲で，それぞれ溶解平衡が得られた。水溶液中の金属，りんそして水素イオンの浱度から溶解度積を算出

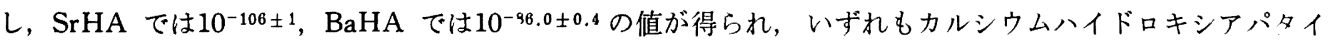
トの値 $10^{-115}$ に比べ大きい。

得られたアパタイトの溶解度積の大きさの順序は，含まれる金属のイオン半径の大きさのそれと一致した。 また三種のイオンの水和エネルギーとアパタイト結晶の格子エネルギーについての考察から，これらアパタ 
イト間の溶解度積の差は水和 エネルギーよりも各アパタイト結晶の格子エネルギーの差によるものと推察さ れた。

\section{文献}

1) Marguerite, F. L. and Kathleen, B : Strontium and fluoride content of surface and inner enamel versus caries prevalence in the Atlantic Coast of the United State of America. Caries Res. 10 : 297-307, 1976.

2) Gedalia, I. Almog, D. and Yariv, S.: Effects of strontium and fluoride uptakes on the solubility of powdered enamel. Caries Res. 11 : 287-292, 1977.

3) Rygh, O.: Recherches sur les oligo-elèménts. I. De I importance du strontium, du baryum et zinc. Bull. Soc. Chim. Biol. 31 : 1052-1061, 1949.

4) Shaw, J. H. and Griffiths, D.: Developme$n$ tal and postdevelopmental influences on incidence of experimental dental caries resulting from dietary supplementation by various elem. ents. Archs. Oral Biol. 5 : 301-322, 1961.

5）青木秀希 : 合成ならびに生体アパタイトの溶解 性と焼結体. 虫歯のシンポジウム II-う蝕感受 性（須賀照一，石井俊文編） p. 82, 口腔保健 協会, 東京, 1977 .

6）倉田茂昭, 藤原 努, 根岸秀幸, 山崎 升, 藤瀬精一：種々の $\mathrm{pH}$ と温度におけるストロ ンチウム, バリウムハイドロキシアパタイトの 生成. 歯基礎誌 24:661-667，1982.

7) Stability constants, Part II. in : Inorganic Ligands (K. W. SYKES) No. 7, p. 57, Metcalfe \& Cooper, London, 1958.
8) Gnepf, H., Gübeli, O. und Schwarzenbach, G., : Stabilitätskonstanten mononuclearer phosphatokomplexe des strontiums. Helv. Chim. Acta 45 : 1171-1183, 1962.

9) Stability constants, part II. in : Inorganic Ligands (K. W. SYKES) No. 7, p. 3, Me tcalfe \& Cooper, London, 1958.

10) International critical Tables (Edward W. Washburn), Vol. 6, p. 152, McGraw-Hill, New York, 1929.

11）未発表

12) 松浦良平 : 現代無機化学講座 7, 溶液の化学, 第 1 版 p. 161，技報堂, 東京, 1971 .

13) Maurice, H. Frere: The solubility of some strontium phosphates. Soil Science Society Proceedings., 1962 : 48-51, 1962.

14) Ronald, M. H. Verbeeck., Miriam Hauben., Harry P. Thun and Verbeek, F.: Solubility and solution behaviour of strontiumhydroxyapatite. Z. Physik. Chem. Neue Folge. Bd. 108, S. 203-215, 1977.

15）化学便覧, 基礎編 II (日本化学会編), 1 版 p. 1264, 丸善, 東京, 1966.

16）化学便覧, 基礎編 II（日本化学会編）, 1 版 p. 807, 丸善, 東京, 1966 .

17）島田 章: 結晶の構造, 第 1 版 p. 22-31, 化学 同人，京都， 1975 .

18）青葉孝昭：骨無機質内の非晶質及びアパタイト 結晶に関するX線結晶学的研究， II. 非晶質成 分の定量に及ぼすアパタイトの結晶格子の乱れ の影響. 歯基礎誌 $20: 603-615,1978$. 